\title{
Method for Determining Stress Sensitivity of Service Dogs
}

\section{Tatyana Vasilyeva, Alexander Kuznetsov, and Natalya Smolyakova}

South Ural State Agrarian University, Troitsk, Russia

\section{Abstract}

Recently, with the development of the dog expert service of the Interior Ministry the issue of the use and application of service dogs is always important, which creates urgency of the issue about selection of dogs for official use. One of the criteria for selection should be the resistance to stresses, and thus the stability of the nervous system. In this article the question of creating a method for evaluating the stress sensitivity, which is taken as a basis the principle of local adaptation syndrome. Also, one of the main objectives of the article is to compare the quality and degree of manifestation of adaptation syndrome with one of the signs of the body's stress response -- eosinopenia.

Corresponding Author:

Tatyana Vasilyeva

phiziology_ugavm@mail.ru

Received: 25 October 2019

Accepted: 15 November 2019

Published: 25 November 2019

Publishing services provided by Knowledge E

(c) Tatyana Vasilyeva et al. This article is distributed under the terms of the Creative Commons Attribution License, which permits unrestricted use and redistribution provided that the original author and source are credited.

Selection and Peer-review under the responsibility of the AgroSMART 2019 Conference Committee.

\section{S OPEN ACCESS}

Keywords: service dogs, sensitivity to stress, the response of eosinophils, a local adaptation syndrome, turpentine.

In increasing the effectiveness of the antiterrorist activities of the units of the Ministry of Internal Affairs of the Russian Federation and other law enforcement agencies of the Russian Federation, the use of dog handlers with service dogs is becoming increasingly important. In this regard, the issue of selection of service dogs, adapted for training and use in difficult climatic and geographical conditions, with increased capabilities, a stable nervous system and low stress sensitivity, is relevant for the cynological service.

The analysis of domestic and foreign scientific literature showed that there are many ways to determine stress sensitivity, but they cannot be transferred to dogs. As for dogs, we cannot find a way to determine the level of stress sensitivity associated with working quality service animals. We have developed a method for determining stress sensitivity. The principle of local adaptive syndrome (LAS) was adopted at the core. It is known that the features of LAS, as a rule, correspond to the nature of the manifestations of the general adaptation syndrome [2--5]. In this regard, animals experience stress sensitivity. An important point in solving this problem was the selection of the dosed stimulus. Search and analysis of the literature will allow us to dwell on refined essential oil (turpentine), which is widely used in various forms for therapeutic and prophylactic purposes [6, 7]. This product is easily dosed, has strong aseptic properties, prevents the spread of 
infection during use and does not require treatment of injection sites, convenient for use with needleless automatic injectors. When administered intradermally, it causes a bright local adaptation syndrome in the form of aseptic inflammation of the skin area and surrounding tissues.

To determine the threshold dose and concentration of the introduced essential oil and the optimal time for assessing the nature of the course of the adaptation syndrome, the following observations were made.

Based on the center of the cynological service of the Ministry of Internal Affairs of Russia in the Kurgan region, from the number of service dogs, a German shepherd breed, 3 groups of 10 were formed at the age of 1.5--6 years each. All animals in the area of the middle of the outer side of the auricle were trimmed with wool and turpentine was injected intradermally with a needle-free MBI-1 injector: in the first group at a dose of 0.025 ; the second is 0.05 ; the third $--0.1 \mathrm{ml}$.

The diameter of the swelling, the thickening of the auricle, the temperature of the skin at the injection site, soreness and redness in comparison with the same area on the other auricle were used as indicators of the nature of the course of the local adaptation syndrome. A caliper was used to measure the thickness and diameter of the swelling, an FT-55 infrared thermometer was used to measure skin temperature, the degree of redness was assessed visually, and the auricle was tender by palpation. The local adaptation syndrome was assessed within 36 hours every three hours, then after 12 and 24 hours until the signs completely disappeared. For the convenience of analysis, assessment and description of the nature of the local adaptation syndrome, the reaction was evaluated in crosses: 0 -complete absence of local reaction; "+" -- swelling is limited, hyperemia is weak, pain is observed upon palpation, but the dog is active, free behavior is not alert, thickening is up to $1.8 \pm 0.19 \mathrm{~mm}$, swelling diameter is up to $12.0 \pm 0.53 \mathrm{~mm}$, temperature is increased by $0.40 \pm 0.02$; assessment -- the reaction is weak; " ++ "-- the swelling is limited, hyperemia is expressed, the skin is damaged at the injection site, the dog is active, is careful during examination, protects the auricle, in some dogs the auricle is incorrectly placed, soreness is significant upon palpation, thickening by $4.10 \pm$ $0.09 \mathrm{~mm}$, swelling diameter $23.4 \pm 0.25$, local temperature higher by $1.0 \pm 0.18$; rating -medium (moderate) reaction; "+++" -- swelling from limited to spilled form, hyperemia is pronounced, swelling and cyanosis on the inside of the auricle, skin is damaged the injection site, incorrect placement of the auricle, tilt of the head towards the damaged auricle, thickening by $5,5 \pm 0.60 \mathrm{~mm}$, the swelling diameter is $36.90 \pm 1.18 \mathrm{~mm}$, the temperature is higher by $2.07 \pm 0.230{ }^{\circ} \mathrm{C}$, the estimate is a strong reaction. 
The results of evaluating the reaction of dogs to the administration of turpentine in various doses are presented in table 1 . The results obtained suggest that turpentine in the tested doses causes a predominantly strong response, in which it is difficult to differentiate the level of stress sensitivity. Moreover, the response to administration of the drug in a dose of $0.1 \mathrm{ml}$ was characterized not only by changes in the auricle along with the administration of the drug, it was also accompanied by general changes in the state of the animals: depression, loss of appetite, vomiting, incorrect placement of the auricle, swelling of the auricle, decreased performance and others signs. In this regard, to test the reaction of animals to the introduction of turpentine in higher doses was impractical.

TABLE 1: The nature of the course of LAS on the introduction of the drug in doses of $0.025,0.05,0.1 \mathrm{ml}$.

\begin{tabular}{|c|c|c|c|c|c|c|c|c|c|c|c|}
\hline \multirow{3}{*}{$\begin{array}{l}\text { Dose of } \\
\text { the drug, } \\
\mathrm{ml}\end{array}$} & \multirow{3}{*}{$\begin{array}{c}\text { General } \\
\text { characteristics } \\
\text { of the reaction }\end{array}$} & \multicolumn{10}{|c|}{ Reaction evaluation time, hours } \\
\hline & & 3 & 6 & 9 & 12 & 15 & 18 & 24 & 36 & 48 & 72 \\
\hline & & \multicolumn{10}{|c|}{ The nature of the manifestation of LAS in the crosses } \\
\hline \multirow[t]{3}{*}{0,025} & weak & 0 & 0 & 0 & + & + & + & + & + & 0 & 0 \\
\hline & medium & 0 & 0 & + & + & ++ & ++ & ++ & ++ & + & 0 \\
\hline & strong & 0 & 0 & ++ & ++ & +++ & +++ & +++ & +++ & ++ & + \\
\hline \multirow[t]{3}{*}{0,05} & weak & 0 & 0 & + & + & + & + & ++ & + & 0 & 0 \\
\hline & medium & 0 & + & + & ++ & ++ & ++ & ++ & ++ & + & + \\
\hline & strong & 0 & + & ++ & +++ & +++ & +++ & +++ & +++ & +++ & ++ \\
\hline \multirow[t]{3}{*}{0,1} & weak & 0 & + & + & + & + & ++ & ++ & + & + & 0 \\
\hline & medium & + & + & ++ & ++ & ++ & +++ & +++ & ++ & ++ & + \\
\hline & strong & + & ++ & +++ & +++ & +++ & +++ & +++ & +++ & +++ & ++ \\
\hline
\end{tabular}

Given these factors, we decided to reduce the irritating effect of turpentine by diluting it with sterile liquid paraffin. To determine the optimal concentration of turpentine, studies were conducted on 6 groups of dogs, a German shepherd breed, aged 1.5 to 6 years, 10 animals in each group. At the same time, turpentine was tested at a concentration of $30 ; 40 ; 50 ; 60 ; 70$ and $80 \%$. Given that turpentine at a dose of 0.025 $\mathrm{ml}$ does not cause a reaction in all animals, we introduced the diluted preparation with a needleless injector at a dose of $0.05 \mathrm{ml}$. The same indicators were used to assess the nature of the course of the local adaptation syndrome.

For a more convenient description of the local process, the characteristics were evaluated in crosses: "0" -- absence of local reaction; "+" -- the swelling is limited, thickening is up to $1.80 \pm 0.19 \mathrm{~mm}$, the diameter of the swelling is up to $12.0 \pm 0.53 \mathrm{~mm}$, 
hyperemia is weak, pain on palpation, the local temperature rises to $0.40 \pm 0.02{ }^{\circ} \mathrm{C}$, the rating is the reaction is weak; "++" -- limited swelling, pain on palpation, hyperemia expressed, temperature increase of $0.1 \pm 0.18{ }^{\circ} \mathrm{C}$, thickening of the shell to $4.0 \pm$ $0.09 \mathrm{~mm}$, swelling diameter up to $23.4 \pm 0.18 \mathrm{~mm}$, estimate -- the reaction is medium (moderate); "+++" -- a pronounced reaction, significant pain, in some cases there are changes in the setting of the auricle, hyperemia is pronounced, a temperature increase of $1.2 \pm 0.14{ }^{\circ} \mathrm{C}$, a thickening of the shell by $5.6 \pm 0.6 \mathrm{~mm}$, swelling diameter more than $36.9 \pm 1.80 \mathrm{~mm}$, in some cases the swelling was diffuse, changes were observed in the general condition of the dog, assessment -- a strong reaction. The research results are presented in table 2 .

From the above data it is seen that a pronounced manifestation of LAS was noted with the introduction of the stimulus at a concentration of $50.0 \%$ and above. At the same time, in the dilution of $50.0 \%$ of LAS by the force of two crosses it was manifested by the 15th, and in the dilution of $60.0 \%$ by the 12th hour and remained at this level until 48 hours, then gradually faded away. At a concentration of $70.0 \%$ and above, LAS with a strength of two crosses arose earlier, by the 9th hour, and by the 12th it was estimated at three crosses and remained pronounced up to 48 hours, then decreased.

Thus, the introduction of turpentine in a mixture with vaseline oil intradermally from the outside of the dog's auricle causes a manifestation of LAS, it should be noted that the severity of LAS depends on the concentration of the drug administered. The most optimal concentration of turpentine was $50.0 \%$. With this breeding, a clear, pronounced reaction is manifested, without compromising the performance of the dogs. Considering that the expressed manifestation of the reaction begins from 15 hours after the administration of the drug and lasts up to 48 hours, inclusive, this period ( 33 hours) should be considered optimal for the manifestation of LAS and its assessment. A very similar response is observed to the administration of turpentine at a concentration of $60.0 \%$. In this regard, this dilution can be used as the range of application of the drug in a dilution of $50.0--60.0 \%$.

After determining the optimal concentration of the stimulus, it was necessary to determine its optimal dose of administration and the optimal time for assessing the nature of the course of LAS. For this purpose, dogs of the German Shepherd breed in the amount of 74 heads in the middle of the outer side of the auricle with a needleless injector (MBI-1) were injected with $50 \%$ turpentine in a dose of $0.05 \mathrm{ml}$. In previous studies, at this dose, the drug caused a different reaction in individual dogs -- from weak to strong. To compare the reaction to the action of the stimulus with the level of stress sensitivity, a universally recognized sign was used -- a decrease in the number of 
TABLE 2: The results of determining the optimal concentration of turpentine to assess the nature of the course of LAS at a dose of $0.05 \mathrm{ml}$.

\begin{tabular}{l|l|c|c|c|c|c|c|c|c|c|c|c|}
$\begin{array}{l}\text { Group } \\
\text { number }\end{array}$ & $\begin{array}{c}\text { Turpentine } \\
\text { concentration }\end{array}$ & \multicolumn{9}{|c|}{ Reaction evaluation time after turpentine administration, hours } \\
\hline 1 & 3 & 6 & 9 & 12 & 15 & 18 & 21 & 24 & 36 & 48 & 72 \\
\hline 2 & 30,0 & 0 & 0 & 0 & + & + & + & + & 0 & 0 & 0 & 0 \\
\hline 3 & 40,0 & 0 & 0 & + & + & + & + & + & + & 0 & 0 & 0 \\
\hline 4 & 50,0 & 0 & + & + & + & ++ & ++ & ++ & ++ & ++ & ++ & + \\
\hline 5 & 60,0 & 0 & + & + & ++ & ++ & ++ & ++ & ++ & ++ & ++ & + \\
\hline 6 & 70,0 & 0 & + & ++ & ++ & +++ & +++ & +++ & +++ & ++ & ++ & ++ \\
\hline & 80,0 & 0 & + & ++ & ++ & +++ & +++ & +++ & +++ & +++ & +++ & ++ \\
\hline
\end{tabular}

eosinophils in the blood (eosinopenia). To determine the number of eosinophils in the blood, we used the classical method S.M. Buckman [1]. Blood for research was taken from the saphenous vein of the lower leg or forearm 2 times: before the administration of turpentine, 36 hours after the injection (during the period of maximum manifestation of the reaction). As a result of the studies, it was found that out of 74 dogs in 35 (47.3\%) animals, after 36 hours, the number of eosinophils in the blood decreased from 747.7 \pm 9.4 to $699.5 \pm 8.5$ or by $6.4 \%$, in $16(21.6 \%)$ dogs with $744.3 \pm 14.5$ to $564.6 \pm 5.2$, or $24.6 \%$, in 23 (31.4\%) animals with $749.97 \pm 9,5$ to $478.3 \pm 4.5$ in $1 \mathrm{~mm}^{3}$ or by 36.2 $\%$ (table 3).

Animals in which there was a decrease in eosinophils by $6.4 \%$ were highly stress resistant, by $24.1 \%$-- with average stress sensitivity, and by $36.2 \%$-- with high stress sensitivity.

After determining the level of stress sensitivity by the percentage of decrease in blood of eosinophils, a second observation was carried out, which consisted of three dogs of 15 goals each formed from the number of dogs with a known stress sensitivity determined by the decrease in the number of eosinophils in the blood. In each group, animals were divided into three more subgroups depending on the level of their stress sensitivity: the first subgroup included dogs with high stress sensitivity, the second -medium, the third -- low, each subgroup 5 goals. All animals were injected intradermally in the middle of the outer surface of the auricle with $50 \%$ turpentine: in the first group at a dose of $0.025 \mathrm{ml}$, the second at $0.05 \mathrm{il}$, and the third at $0.075 \mathrm{ml}$.

The diameter of the swelling, the thickening of the auricle, the temperature of the skin at the injection site, soreness and redness in comparison with the same area on the other auricle were used as indicators of the nature of the response (LAS). To evaluate the indicators used the same methods and devices that are described above. 
TABLE 3: Results of a comparison of a decrease in the number of eosinophils in the blood of service dogs with the nature of the manifestation of LAS on the administration of $50 \%$ turpentine at a dose of $0.05 \mathrm{ml}$.

\begin{tabular}{|c|c|c|c|c|c|}
\hline \multirow{3}{*}{$\begin{array}{l}\text { Degree of } \\
\text { stress } \\
\text { sensitivity } \\
\text { weak }\end{array}$} & \multicolumn{2}{|c|}{ LAS indicator } & \multicolumn{3}{|c|}{$\begin{array}{c}\text { The number of eosinophils in the blood, } \\
\text { units of cells }\end{array}$} \\
\hline & \multicolumn{2}{|c|}{ After 36 hours } & \multirow{2}{*}{$\begin{array}{l}\text { Before testing } \\
747,7 \pm 9,4\end{array}$} & \multirow{2}{*}{$\begin{array}{c}\text { After } 36 \text { hours } \\
699,5 \pm 8,5\end{array}$} & \multirow{2}{*}{$\begin{array}{c}\% \\
\text { reduction } \\
6,4\end{array}$} \\
\hline & Swelling, mm & $1,8 \pm 0,19$ & & & \\
\hline & Swelling diameter, $\mathrm{mm}$ & $12,3 \pm 0,53$ & & & \\
\hline & Hyperemia & insignificant & & & \\
\hline & Soreness & on palpation & & & \\
\hline & $\begin{array}{l}\text { Increase in local } \\
\text { temperature, }{ }^{\circ} \mathrm{C}\end{array}$ & $0,4 \pm 0,02$ & & & \\
\hline \multirow[t]{5}{*}{ medium } & Swelling, mm & $4,1 \pm 0,09$ & $744,3 \pm 14,5$ & $564,6 \pm 5,2$ & 24,1 \\
\hline & Swelling diameter, $\mathrm{mm}$ & $23,4 \pm 0,25$ & & & \\
\hline & Hyperemia & moderate & & & \\
\hline & Soreness & $\begin{array}{l}\text { eliminated from } \\
\text { palpation }\end{array}$ & & & \\
\hline & $\begin{array}{l}\text { Increase in local } \\
\text { temperature, }{ }^{\circ} \mathrm{C}\end{array}$ & $1,0 \pm 0,18$ & & & \\
\hline \multirow[t]{5}{*}{ strong } & Swelling, mm & $5,6 \pm 0,6$ & $749,97 \pm 9,5$ & $478,3 \pm 4,5$ & 36,2 \\
\hline & Swelling diameter, mm & $36,9 \pm 1,80$ & & & \\
\hline & Hyperemia & pronounced & & & \\
\hline & Soreness & $\begin{array}{l}\text { on palpation } \\
\text { squeals }\end{array}$ & & & \\
\hline & $\begin{array}{l}\text { Increase in local } \\
\text { temperature, }{ }^{\circ} \mathrm{C}\end{array}$ & $1,2 \pm 0,14$ & & & \\
\hline
\end{tabular}

LAS assessment was performed within 72 hours: after 3; 6; 9; 12; fifteen; eighteen; 24; 36; 48; 72 hours For the convenience of analysis, evaluation and description, the nature of the local adaptation syndrome was evaluated in crosses: 0 -- complete absence of local reaction; "+" -- the swelling is limited, hyperemia is weak, pain is observed upon palpation, but the dog is active, the behavior is not alert, the thickening is increased to $1.8+0.19$, the swelling diameter is up to $12.3+0.53$, the temperature is not raised more than $0.4+0.09{ }^{\circ} \mathrm{C}$; assessment -- the reaction is weak; "++" -- the swelling is limited, hyperemia is expressed, the skin is damaged at the injection site, the dog is active, is careful during the examination, protects the auricles, in some dogs the auricle is incorrectly positioned, pain on palpation is significant, thickening is increased by 4.1 $+0.09 \mathrm{~mm}$, the swelling diameter is $23.4+0.25$, the local temperature is higher by $1.0+0.18^{\circ} \mathrm{C}$, the rating is a medium (moderate) reaction; "+++" -- swelling from limited 
to spilled form, hyperemia is pronounced, swelling and cyanosis on the inside of the auricle, skin is damaged at the injection site, incorrect placement of the auricle, tilt of the head towards the damaged auricle, thickening increased by $56+0.60 \mathrm{~mm}$, the swelling diameter is $36.9 \pm 1.80 \mathrm{~mm}$, the temperature is higher by $1.2+0.140{ }^{\circ} \mathrm{C}$, the estimate is a strong reaction.

The results of the assessment of LAS for the introduction of $50 \%$ turpentine in various doses are presented in table 4.

TABLE 4: The nature of the reaction of dogs with different levels of stress sensitivity to the introduction of $50 \%$ turpentine in different doses.

\begin{tabular}{|c|c|c|c|c|c|c|c|c|c|c|c|}
\hline \multirow{2}{*}{$\begin{array}{l}\text { Dose of } \\
\text { the drug, } \\
\mathrm{ml}\end{array}$} & Stress level & \multicolumn{10}{|c|}{ Reaction evaluation time, hour } \\
\hline & & 3 & 6 & 9 & 12 & 15 & 18 & 24 & 36 & 48 & 72 \\
\hline & & \multicolumn{10}{|c|}{ The nature of the manifestation of LAS in the crosses } \\
\hline \multirow[t]{3}{*}{0,025} & low & 0 & 0 & + & ++ & + & 0 & 0 & 0 & 0 & 0 \\
\hline & average & 0 & 0 & ++ & ++ & + & + & 0 & 0 & 0 & 0 \\
\hline & strong & 0 & 0 & ++ & +++ & +++ & ++ & ++ & ++ & ++ & + \\
\hline \multirow[t]{3}{*}{0,05} & low & 0 & 0 & ++ & ++ & ++ & + & 0 & 0 & 0 & 0 \\
\hline & average & 0 & + & ++ & ++ & +++ & ++ & ++ & ++ & ++ & + \\
\hline & strong & 0 & + & ++ & +++ & +++ & +++ & +++ & +++ & +++ & ++ \\
\hline \multirow[t]{3}{*}{0,075} & low & 0 & + & ++ & ++ & ++ & + & $0+$ & 0 & 0 & 0 \\
\hline & average & + & + & ++ & +++ & +++ & ++ & ++ & ++ & ++ & + \\
\hline & strong & + & ++ & +++ & +++ & +++ & +++ & +++ & +++ & +++ & ++ \\
\hline
\end{tabular}

An analysis of the results allows us to conclude that $50 \%$ turpentine, injected intradermally, causes a local adaptation syndrome, the severity of which depends on the dose and the level of stress sensitivity of the dog. The optimal dose of turpentine, causing an optimal response, is $0.05-0.075 \mathrm{ml}$. At this dose, the drug causes a pronounced inflammatory reaction, the distinctive features of which, depending on the stress sensitivity, are clearly manifested by 24 hours from the moment of drug administration, last up to 72 hours and can be used to assess the level of stress sensitivity of dogs. The developed method is simple to implement, cheap, can easily be introduced into production for the selection and selection of service dogs according to the level of stress sensitivity. 


\section{References}

[1] Buckman, S.M. (1958). To the method of counting eosinophils in peripheral blood. Laboratory, no. 5, p. 13--15.

[2] Kuznetsov, A.I. (1990). Metabolic characteristics of stress-sensitive sows in industrial technology. RZ pig breeding, no. 4, p. 4.

[3] Kuznetsov, A.I., Sunagatullin F.A. (1991). The method of assessment of stress sensitivity. RJ Pig, no. 1, p. 6.

[4] Miftakhutdinov, A.V., Terman, A.N. Methodological basis for determining the stress sensitivity of chickens by modeling the local adaptation syndrome. Materials of the VIII International scientific-practical conference of young scientists "Actual and new directions of agricultural science", dedicated to the 75th anniversary of Professor A.T. Farnieva. Part 2. Vladikavkaz, ed. Mountain State Agrarian University, pp. 2--1, $120--122$.

[5] Miftakhutdinov, A.V. (2014). Experimental approaches to the diagnosis of stress in poultry farming (review). Agricultural Biology, no. 2, pp. 20--30.

[6] Mashkovsky, M.D. Medicines, part 11. Moscow: Medicine, 1978, 198 p.

[7] Chervyakov, D.K., Evdokimov, P.D., Vishker, A.S. (1977). Medicines in Veterinary Medicine. Moscow: Kolos, pp. 85--87. 